\title{
New Chemical Modification of Polymers with Pendant Chloromethyl Groups Using 1,8-Diazabicyclo-[5.4.0]-7-undecene
}

\author{
Atsushi Kameyama, Misao Suzuki, Kazuhiro Ozaki, and Tadatomi Nishikubo ${ }^{\dagger}$ \\ Department of Applied Chemistry, Faculty of Engineering, Kanagawa University, \\ Rokkakubashi, Kanagawa-ku, Yokohama 221, Japan
}

(Received September 26, 1995)

\begin{abstract}
The esterification reaction of poly[( $p$-chloromethyl)styrene] (PCMS) with benzoic acid and acetic acid proceeded very smoothly to give the corresponding polymers with pendant ester residues using 1,8-diazabicyclo-[5.4.0]-7undecene (DBU) as an organic base even at $30^{\circ} \mathrm{C}$ in aprotic polar solvents such as $N, N$-dimethylformamide (DMF), $N$-methyl-2-pyrrolidone, and dimethyl suloxide (DMSO). The reaction of poly(2-chloroethyl vinyl ether) (PCEVE) and poly(epichlorohydrin) $(\mathrm{PECH})$ with benzoic acid in the presence of DBU in DMF also gave corresponding polymers with pendant benzoate moieties. However, the reactivities of PCEVE and PECH were lower than that of PCMS. Furthermore, the reaction of PCMS with $\mathrm{N}$-protected amino acids such as Boc-L-alanine, Cbz-L-alanine, and Bz-DL-alanine afford corresponding polymers with pendant amino acid residues in high conversions using DBU in DMSO. From these results, it was concluded that DBU is the extremely useful organic base for the esterfication reaction of the pendant chloromethyl groups in the polymers with carboxylic acids under mild reaction conditions.

KEY WORDS Esterification Reaction / Pendant Chloromethyl Group / Carboxylic Acid / 1,8-diazabicyclo-[5.4.0]-7-undecene / Mild Reaction Condition /
\end{abstract}

Polymers with chloromethyl group in the side chains are useful starting materials ${ }^{1}$ for the synthesis of various functional polymers. The pendant chloromethyl group in the polymer can be modified readily by the substitution reactions with some nucleophilic reagents. The most commonly method employed for the chemical modification of the pendant chloromethyl group is the substitution reaction using phase transfer catalysts ${ }^{2}$ (PTC). The characteristic of the substitution reaction of pendant chloromethyl groups in the polymers in the presence of PTC has been investigated in detail. ${ }^{3-6}$ This reaction system can also be widely applied for the synthesis of certain functional polymers such as photo-resists, ${ }^{7}$ photoresponsive polymers, ${ }^{8}$ and polymeric photosensitizers ${ }^{9}$ under mild reaction conditions. However, the employment of alkali metal salts of nucleophilic reagents is ordinarily necessary for the reaction with pendant chloromethyl groups in the polymers. Furthermore, it was found that the reaction of polymeric anions such as alkali metal salts of poly(methacrylic acid) with low molecular weight alkyl halides dose not proceed ${ }^{10,11}$ to give the corresponding poly(methacrylic ester)s in high conversion using PTC at the elevated temperature. It is very difficult to move the polymeric anions from aqueous layer and solid layer to organic layer even using PTC.

Meanwhile, the authors found ${ }^{10,12}$ recently that the substitution reaction of poly(methacrylic acid) with certain low molecular weight alkyl halides proceed successfully to give the corresponding poly(methacrylic ester)s with pendant functional groups in very high conversions using 1,8-diazabicyclo-[5.4.0]-7-undecene (DBU) in aprotic polar solvents such as $N, N$-dimethylformamide (DMF) and dimethyl sulfoxide (DMSO) under mild reaction conditions, which is a very convenient and interesting method for the chemical modification of polymers having pendant carboxylic acid

\footnotetext{
$\dagger$ To whom all correspondence should be addressed.
}

groups. This reaction system was also employed ${ }^{13}$ for the synthesis of polyesters by the reaction of dicarboxylic acids with alkylene dihalides.

It is reasonable that DBU method might be utilized widely for the chemical modification of pendant chloromethyl groups in the polymers. This article reports on the reaction of pendant chloromethyl groups in various polymers with certain carboxylic acids using DBU in aprotic polar solvents under mild reaction conditions.

\section{EXPERIMENTAL}

\section{Materials}

All solvents, DBU, triethylamine (TEA), pyridine, and acetic acid were used after distillation using $\mathrm{CaH}_{2}$. Benzoic acid, 4-( $N, N$-dimethylamino)pyridine (DMAP), and tetrabutylammonium bromide (TBAB) were used after recrystallization from appropriate solvents. Sodium benzoate was prepared by the reaction of benzoic acid with sodium hydroxide in methanol. Reagent grade amino acid derivatives such as Boc-L-alanine, Cbz-L-alanine, and Bz-DL-alanine were used without further purification. Poly[( $p$-chloromethyl)styrene $]$ (PCMS) (inherent viscosity: $0.16 \mathrm{dlg}^{-1}$, which was measured at $0.5 \mathrm{~g} \mathrm{dl}^{-1}$ in $\mathrm{DMF}$ at $30^{\circ} \mathrm{C}$ ) was prepared in $72 \%$ yield by the radical polymerization of ( $p$ chloromethyl)styrene using azobisisobutyronitrile as an initiator in toluene at $60^{\circ} \mathrm{C}$ for $5 \mathrm{~h}$, and then at $80^{\circ} \mathrm{C}$ for $3 \mathrm{~h}$. Poly(2-chloroethyl vinyl ether) (PCEVE) (inherent viscosity, $0.78 \mathrm{dl} \mathrm{g}^{-1}$; measured at $0.5 \mathrm{~g} \mathrm{dl}^{-1}$ in DMF at $30^{\circ} \mathrm{C}$ ) was obtained in $93 \%$ yield by the cationic polymerization of 2-chloroethyl vinyl ether using $\mathrm{BF}_{3}$. $\mathrm{OEt}_{2}$ as a catalyst in toluene at $-65^{\circ} \mathrm{C}$ for $1 \mathrm{~h}$. Commercial poly(epichlorohydrin) ( $\mathrm{PECH})$ (inherent viscosity, $6.49 \mathrm{dl} \mathrm{g}^{-1}$; measured at $0.5 \mathrm{~g} \mathrm{dl}^{-1}$ in DMF at $30^{\circ} \mathrm{C}$ ) was purified by the reprecipitation from acetone into methanol. 


\section{Measurements}

${ }^{1} \mathrm{H}$ NMR spectra were obtained on a JEOL EX-90 and a JEOL FX-200 operating in the pulsed Fouriertransform (FT) modes using tetramethylsilane (TMS) as an internal standard in chloroform- $d_{3}$. IR spectra were recorded on a JASCO IR-700. Specific rotation $[\alpha]_{\mathrm{D}}^{25}$ of the obtained polymer by the reaction of PCMS with Boc-L-alanine was measured by a JASCO DIP-140 model in THF $\left(1.0 \mathrm{~g} \mathrm{dl}^{-1}\right)$ at $25^{\circ} \mathrm{C}$.

Typical Procedure for the Reaction of Pendant Chloromethyl Group in the Polymer with Carboxylic Acid

PCMS $(0.763 \mathrm{~g} ; 5 \mathrm{mmol})$ was dissolved in $10 \mathrm{ml}$ of DMSO, and then benzoic acid $(0.611 \mathrm{~g} ; 5 \mathrm{mmol})$ and DBU $(0.761 \mathrm{~g} ; 5 \mathrm{mmol})$ were added into the solution. The mixture was stirred at $60^{\circ} \mathrm{C}$ for $1 \mathrm{~h}$, and poured into methanol to precipitate the polymer, which was reprecipitated twice from THF into methanol, filtered, and dried in vacuo at $60^{\circ} \mathrm{C}$. Yield of the resulting polymer was $0.79 \mathrm{~g}$. Degree of esterification was $93 \%$ (which was determined by elemental analysis of chlorine). Inherent viscosity of the resulting polymer was $0.22 \mathrm{dlg}^{-1}$, measured at $0.5 \mathrm{~g} \mathrm{dl}^{-1}$ in DMF at $30^{\circ} \mathrm{C}$. IR (film): 1723 $(\mathrm{C}=\mathrm{O})$ and $1278 \mathrm{~cm}^{-1}(\mathrm{C}-\mathrm{O}-\mathrm{C}) .{ }^{1} \mathrm{H} \mathrm{NMR}\left(\mathrm{CDCl}_{3}\right)$ : $1.0-2.3$ (br, $3 \mathrm{H}, \mathrm{CH}_{2}-\mathrm{CH}$ in the main chain), 4.2-4.5 (s, $\mathrm{CH}_{2} \mathrm{Cl}$ ), $5.2\left(\mathrm{~s}, \mathrm{CH}_{2} \mathrm{O}\right.$ ), and $6.2-8.2 \mathrm{ppm}$ (br, aromatic protons).

\section{RESULTS AND DISCUSSION}

\section{Reaction of PCMS with Carboxylic Acids Using DBU}

The reaction of PCMS with benzoic acid, as an aromatic carboxylic acid, using equimolar DBU was carried out in various solvents (conc.: $0.5 \mathrm{~mol}^{-1}$ ) at $60^{\circ} \mathrm{C}$ for $1 \mathrm{~h}$. The results are summarized in Table $\mathrm{I}$. The esterification of the pendant chloromethyl group of

Table I. Solvent effect on the reaction of PCMS with benzoic acid using DBU ${ }^{\mathrm{a}}$

\begin{tabular}{|c|c|c|c|c|}
\hline \multirow{2}{*}{ Solvent } & Yield & Chlorine content & $\begin{array}{c}\text { Degree of } \\
\text { esterification }\end{array}$ & $\eta_{\mathrm{sp}} / c^{\mathrm{c}}$ \\
\hline & $\mathrm{g}$ & $\mathrm{mgg}^{-1}$ & $\%$ & $\mathrm{dl} \mathrm{g}^{-1}$ \\
\hline DMF & 0.83 & 16.6 & 86 & 0.22 \\
\hline DMSO & 0.79 & 11.0 & 93 & 0.18 \\
\hline NMP & 0.82 & 15.9 & 90 & 0.14 \\
\hline DMAc & 0.79 & 21.8 & 87 & 0.14 \\
\hline Toluene & 0.63 & 35.2 & 72 & 0.58 \\
\hline EtOAc & 0.82 & 30.2 & 81 & 0.40 \\
\hline THF & 0.67 & 35.2 & 72 & 0.30 \\
\hline
\end{tabular}

a The reaction was carried out with PCMS $(5 \mathrm{mmol})$ and benzoic acid $(5 \mathrm{mmol})$, using DBU $(5 \mathrm{mmol})$ in the solvent $(10 \mathrm{ml})$ at $60^{\circ} \mathrm{C}$ for $1 \mathrm{~h}$. ${ }^{\mathrm{b}}$ Calculated from chlorine analysis. ${ }^{\mathrm{c}}$ Measured at $0.5 \mathrm{~g} \mathrm{dl}^{-1}$ in DMF at $30^{\circ} \mathrm{C}$.

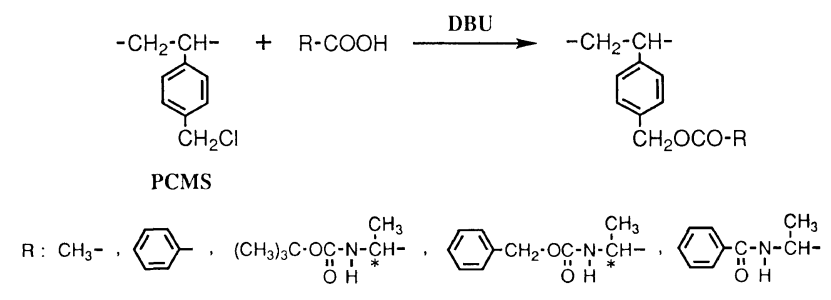

Scheme 1.
PCMS proceeded smoothly in ethyl acetate (EtOAc), $\mathrm{THF}$, and toluene. Aprotic polar solvents enhanced effectively the reaction, for example, the reaction in DMF or $N$-methyl-2-pyrrolidone (NMP) proceeded in $86 \%$ and $90 \%$ degrees of esterification, respectively. In particular, the reaction in DMSO gave the polymer with the highest degree of esterification ( $92 \%)$, which was determined by elemental analysis of chlorine analysis (Scheme 1). The degree of esterification of the polymer was also confirmed by the intensity ratio of methylene protons of the side chain.

As shown in Figure 1, the reaction in DMSO proceeded rapidly even at $30^{\circ} \mathrm{C}$. The degree of esterification at $5 \mathrm{~min}$ was $55 \%$, and that reached to $80 \%$ for $45 \mathrm{~min}$. It was also found that the reaction was enhanced efficiently by elevating the reaction temperature. The degrees of esterification at $5 \mathrm{~min}$ at $60^{\circ} \mathrm{C}$ and $80^{\circ} \mathrm{C}$, were $65 \%$ and $82 \%$, respectively. Moreover, the reaction proceeded quantitatively in DMSO at $80^{\circ} \mathrm{C}$ for $60 \mathrm{~min}$.

The reaction of PCMS with acetic acid as an aliphatic acid using DBU was also examined in DMF (Figure 2). When the reaction was conducted at $30^{\circ} \mathrm{C}$, the degree of esterification was $86 \%$ for $60 \mathrm{~min}$. The increase of the temperature effectively enhanced the reaction. It was shown that the reaction proceeded quantitatively at $60^{\circ} \mathrm{C}$ for $60 \mathrm{~min}$ and at $80^{\circ} \mathrm{C}$ for $30 \mathrm{~min}$, respectively.

Thus, the reaction of PCMS with carboxylic acids using DBU as a base proceeded very smoothly under the mild

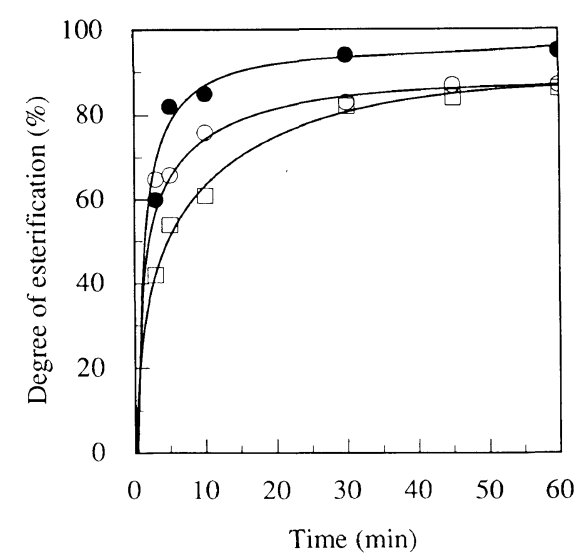

Figure 1. Reaction of PCMS with benzoic acid using DBU in DMSO: $(\square)$, at $30^{\circ} \mathrm{C} ;(\bigcirc)$, at $60^{\circ} \mathrm{C} ;(\bullet)$, at $80^{\circ} \mathrm{C}$.

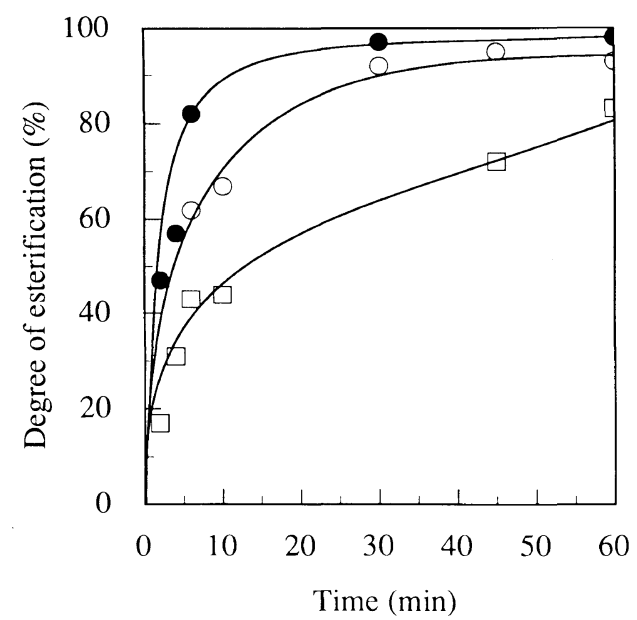

Figure 2. Reaction of PCMS with acetic acid using DBU in DMF: $(\square)$, at $30^{\circ} \mathrm{C} ;(\bigcirc)$, at $60^{\circ} \mathrm{C} ;(\bullet)$, at $80^{\circ} \mathrm{C}$. 
conditions to provide corresponding polymers with ester residues in the side chain. It was also suggested that the reaction of PCMS with acetic acid proceeded more readily than that with benzoic acid. The higher reactivity of acetic acid would be ascribed to the higher nucleophilicity of the corresponding carboxylate, which is generated by the reaction with DBU, than that of benzoic acid.

\section{Effect of Organic Bases on the Reaction of PCMS with Benzoic Acid}

The reaction of PCMS with benzoic acid was examined using various organic bases in DMF at $60^{\circ} \mathrm{C}$ for $1 \mathrm{~h}$ (Table II). When the reaction was carried out using TEA $\left(\mathrm{p} K_{\mathrm{a}}=10.9\right)$ as a base, the degree of esterification was $43 \%$. From the ${ }^{1} \mathrm{H}$ NMR spectrum of the obtained polymer, it was found that the reaction of the used triethylamine with the pendant chloromethyl group partially took place as a side reaction during the reaction. In the case of the reaction using pyridine $\left(\mathrm{p} K_{\mathrm{a}}=5.19\right)$ or DMAP ( $\left.\mathrm{p} K_{\mathrm{a}}=6.04\right)$, the reaction did not proceed. The ${ }^{1} \mathrm{H}$ NMR data of the resulting products of the reaction suggested that the esterification did not occur, and the reaction of the chloromethyl group with the used bases proceeded predominantly to form the $\mathrm{N}$-alkyl pyridinium residue in the side chain of PCMS.

The reactivity and selectivity of the organic bases would be explained concerning the basicity of the used bases. DBU is the most strong base among those bases, which was supported based on the $\mathrm{p} K_{\mathrm{a}}$ value $\left(\mathrm{p} K_{\mathrm{a}}=11.5\right)$. Thus, it is considered that the hard base DBU reacts selectively with carboxylic acids to produce the corresponding carboxylates, and then the generated carboxylate attacks the pendant chloromethyl group in a $S_{N 2}$ reaction mode. On the other hand, the aromatic soft bases such as pyridine and DMAP react preferentially with the chloromethyl group, which is regarded as a soft acidic functional group, to produce the corresponding $N$-alkyl pyridinium derivatives. In the case of triethylamine, that is relatively hard base, the reactions of DBU with carboxylic acids and the chloromethyl group proceed competitively.

It is well known ${ }^{4}$ that the reaction of PCMS with sodium benzoate proceeds smoothly using PTC. Therefore, the reactivity of PCMS with benzoic acid and sodium benzoate were examined using DBU as the organic base and TBAB as the PTC, respectively, in $\mathrm{DMF}$ at $60^{\circ} \mathrm{C}$ (Figure 3). Interestingly, the reaction with

Table II. Reaction of PCMS with benzoic acid using various bases ${ }^{a}$

\begin{tabular}{|c|c|c|c|}
\hline Base & Yield & Chlorine content & $\begin{array}{c}\text { Degree of } \\
\text { esterification }\end{array}$ \\
\hline $\mathrm{p} K_{\mathrm{a}}$ & $\mathrm{g}$ & $\mathrm{mg} \mathrm{g}^{-1}$ & $\%$ \\
\hline DBU (11.5) & 0.83 & 16.6 & 86 \\
\hline TEA (10.9) & 0.62 & 98.3 & $43^{\mathrm{c}}$ \\
\hline Pyridine (5.19) & 0.23 & 167.3 & Trace \\
\hline DMAP (6.04) & 0.67 & - & Trace \\
\hline
\end{tabular}

${ }^{a}$ The reaction was carried out with PCMS $(5 \mathrm{mmol})$ and benzoic acid $(5 \mathrm{mmol})$ using the base $(5 \mathrm{mmol})$ in DMF $(10 \mathrm{ml})$ at $60^{\circ} \mathrm{C}$ for $1 \mathrm{~h}$. ${ }^{\mathrm{b}}$ Calculated from chlorine analysis. ${ }^{\mathrm{c}}$ Calculated from chlorine analysis and elemental analysis of nitrogen. benzoic acid using DBU showed higher rate than the reaction with sodium benzoate using TBAB.

These results mean that DBU is the extremely useful organic base for the selective esterification of the pendant chloromethyl groups of PCMS with carboxylic acids.

\section{Esterification of Various Reactive Polymers with Benzoic Acid Using DBU}

The reaction of certain polymers with pendant chlorometyl groups such as PCEVE and PECH with benzoic acid in the presence of DBU was performed in DMF at $60^{\circ} \mathrm{C}$ for $24 \mathrm{~h}$. As summarized in Table III, the reaction of PCMS with benzoic acid proceeded smoothly to yield the polymer esterified with $86 \%$ conversion even for $1 \mathrm{~h}$. In the reaction of PCEVE and $\mathrm{PECH}$ with benzoic acid under the same conditions, the degrees of esterification were 75 and $55 \%$ for $24 \mathrm{~h}$ (Scheme 2). That is, these polymers with pendant

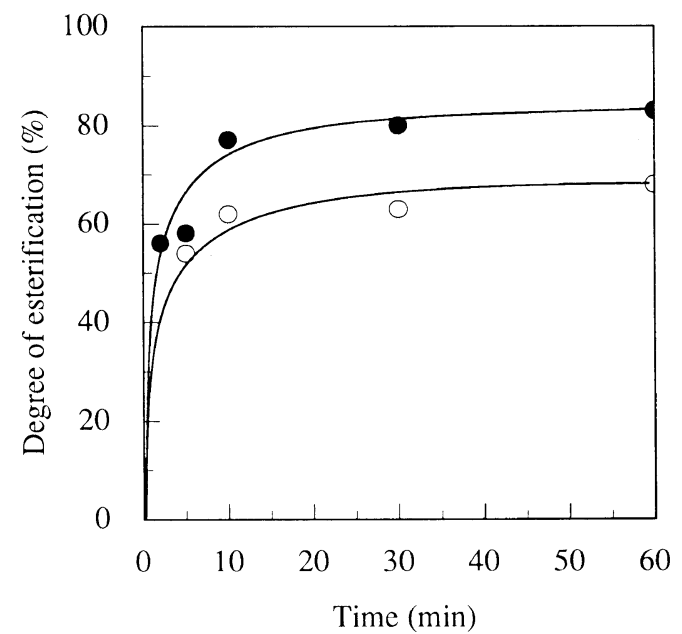

Figure 3. Reaction of PCMS with benzoic acid derivatives in DMF at $60^{\circ} \mathrm{C}$ : $(\bigcirc)$, with benzoic acid using DBU; $(\bigcirc)$, with sodium benzoate using TBAB.

Table III. Reaction of various polymers with benzoic acid using DBU $^{\mathrm{a}}$

\begin{tabular}{|c|c|c|c|c|}
\hline \multirow{2}{*}{ Polymer } & Yield & Chlorine content & $\begin{array}{c}\text { Degree of } \\
\text { esterification }^{b}\end{array}$ & $\eta_{\mathrm{sp}} / c^{\mathrm{c}}$ \\
\hline & $\mathrm{g}$ & $\mathrm{mg} \mathrm{g}^{-1}$ & $\%$ & $\mathrm{dl} \mathrm{g}^{-1}$ \\
\hline $\mathrm{PCMS}^{\mathrm{d}}$ & 0.83 & 16.6 & 86 & 0.22 \\
\hline PCEVE & 0.78 & 42.2 & 75 & 1.10 \\
\hline PECH & 0.47 & 116.3 & 55 & 3.76 \\
\hline
\end{tabular}

${ }^{a}$ The reaction was carried out with the polymer $(5 \mathrm{mmol})$ and benzoic acid $(5 \mathrm{mmol})$ using DBU $(5 \mathrm{mmol})$ in DMF $(10 \mathrm{ml})$ at $60^{\circ} \mathrm{C}$ for $24 \mathrm{~h}$. ${ }^{\mathrm{b}}$ Calculated from chlorine analysis. ${ }^{\mathrm{c}}$ Measured at $0.5 \mathrm{~g} \mathrm{dl}^{-1}$ in DMF at $30^{\circ} \mathrm{C}$. ${ }^{\mathrm{d}}$ The reaction was carried out at $60^{\circ} \mathrm{C}$ for $1 \mathrm{~h}$.

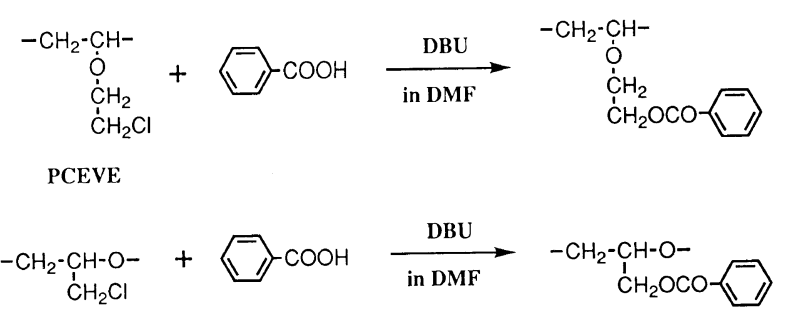

Scheme 2. 
chloromethyl moiety were esterified readily with carboxylic acid using DBU as the organic strong base. It was also found that the reactivity of these polymers in the esterification with carboxylic acid using DBU was decreased in the following order, PCMS $>$ PCEVE $>$ $\mathrm{PECH}$. The same results have been obtained ${ }^{4-6}$ on the reactions of PCMS, PCEVE, and PECH with potassium carboxylates using PTC. These results mean that PCMS with pendant benzyl chloride residue has higher reactivity than $\mathrm{PCEVE}$ and $\mathrm{PECH}$ with pendant alkyl

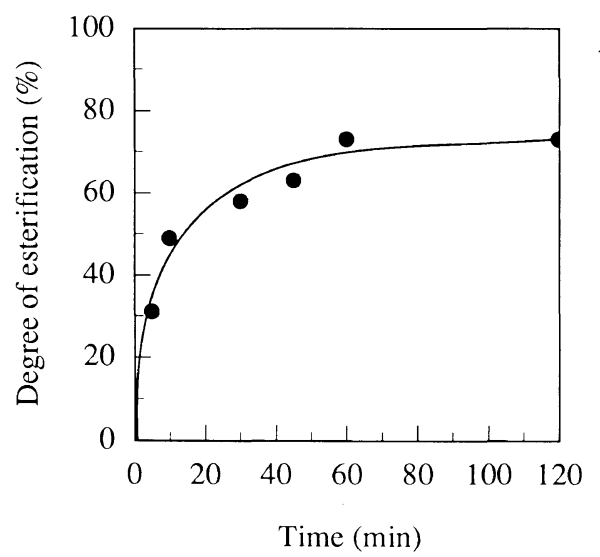

Figure 4. Reaction of PCMS with Boc-L-alanine using DBU in DMF at $60^{\circ} \mathrm{C}$.

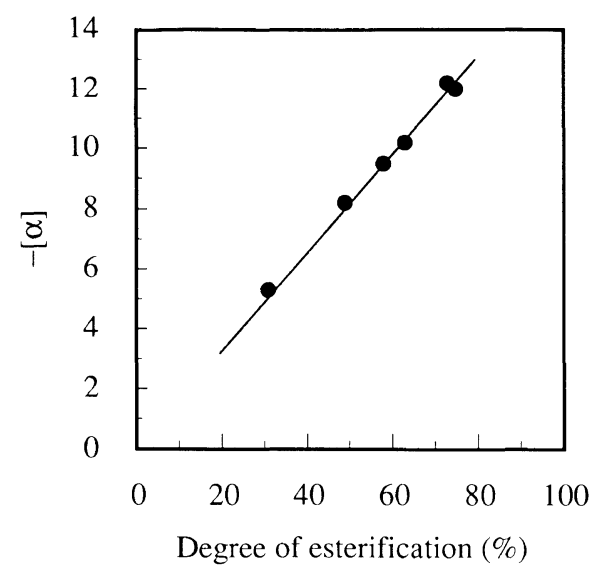

Figure 5. Specific rotation of the polymer obtained by the reaction of PCMS with Boc-L-alanine using DBU.

Table IV. Reaction of PCMS with $N$-protected amino acid using DBU ${ }^{a}$

\begin{tabular}{|c|c|c|c|c|}
\hline \multirow{2}{*}{$\begin{array}{l}N \text {-Protected } \\
\text { amino acid }\end{array}$} & Yield & $\begin{array}{l}\text { Chlorine } \\
\text { content }\end{array}$ & $\begin{array}{c}\text { Degree of } \\
\text { esterification }^{b}\end{array}$ & $\eta_{\mathrm{sp}} / c^{\mathrm{c}}$ \\
\hline & $\mathrm{g}$ & $\mathrm{mg} \mathrm{g}^{-1}$ & $\%$ & $\mathrm{dlg}^{-1}$ \\
\hline Boc-L-alanine & 0.34 & 34.3 & 78 & 0.15 \\
\hline Cbz-L-alanine & 0.68 & 15.5 & 86 & 0.26 \\
\hline Bz-DL-alanine & 0.45 & 23.1 & 82 & 0.16 \\
\hline
\end{tabular}

${ }^{a}$ The reaction was carried out with PCMS $(2.5 \mathrm{mmol})$ and $N$-protected amino acid $(2.5 \mathrm{mmol})$ using DBU $(2.5 \mathrm{mmol})$ in DMSO $(5 \mathrm{ml})$ at $60^{\circ} \mathrm{C}$ for $1 \mathrm{~h} .{ }^{\mathrm{b}}$ Calculated from chlorine analysis. ${ }^{\mathrm{c}}$ Measured at $0.5 \mathrm{~g} \mathrm{dl}^{-1}$ in DMF at $30^{\circ} \mathrm{C}$. chloride residue. Furthermore, the reactivity of the pendant chloromethyl groups was strongly affected by the steric hindrance of the polymer main chain, and PCEVE with long spacer chain showed higher reactivity than PECH.

\section{The Reaction of PCMS with N-Protected Amino Acids Using $D B U$}

The reaction of PCMS with Boc-L-alanine was carried out using equimolar DBU in DMF at $60^{\circ} \mathrm{C}$ (Scheme 1). As shown in Figure 4, the reaction proceeded smoothly, and the degrees of esterification at $10 \mathrm{~min}$ and $60 \mathrm{~min}$ were about $50 \%$ and $75 \%$, respectively. In the late stage of the reaction, the reaction seems to be inhibited by a steric hindrance of the incorporated bulky Boc-L-alanine residue in the side chain. The specific rotation of the resulting polymer increased linearly to the degree of esterification (Figure 5). This means that the specific rotation was in proportion to the content of the Boc-L-alanine residue in the side chain.

The reaction of PCMS with three $N$-protected amino acids was conducted in DMSO at $60^{\circ} \mathrm{C}$, and the results are summarized in Table IV. When the reactions of PCMS with Boc-L-alanine and Cbz-L-alanine were carried out, the corresponding polymers with 78 and 86 $\%$ of degrees of esterification were obtained, respectively. The reaction with Bz-DL-alanine also proceeded smoothly in $82 \%$ of degree of esterification to give the polymer. Thus, it was demonstrated that the reaction of PCMS using DBU was useful route for the introduction of $\mathrm{N}$-protected amino acid residues in the side chain.

\section{REFERENCES}

1. 1. For example: a) M. Okawara, "Polymer Reactions," Kagaku Dojin, Kyoto, 1972. b) The Society of Polymer Science, Japan, Ed., "Synthesis and Reaction of Polymers (2)," Kyoritu Shupan, Tokyo, 1991.

2. J. M. J. Fréchet, M. D. de Smet, and M. J. Farrall, J. Org. Chem., 44, 1774 (1979).

3. T. Nishikubo, T. Iizawa, K. Kobayashi, and M. Okawara, Makromol. Chem., Rapid Commun., 1, 765 (1980).

4. T. Nishikubo, T. Iizawa, K. Kobayashi, Y. Masuda, and M Okawara, Macromolecules, 16, 772 (1983).

5. T. Iizawa, T. Nishikubo, Y. Masuda, and M. Okawara, Macromolecules, 17, 992 (1984).

6. T. Iizawa, T. Nishikubo, M. Ichikawa, Y. Sugawara, and M. Okawara, J. Polym. Sci., Polym. Chem. Ed., 23, 1893 (1985).

7. T. Nishikubo, T. Iizawa, and E. Takahashi, "Materials for Microlithography," ACS Symposium Series, 266, L. F. Thompson, C. G. Willson, and J. M. J. Frechet, Ed., The American Chemical Society, Washington, D.C., 1984.

8. T. Nishikubo, T. Shimokawa, and A. Sahara, Macromolecules, 22, 8 (1989)

9. T. Nishikubo, J. Uchida, K. Matsui, and T. Iizawa, Macromolecules, 21, 1583 (1988).

10. T. Shimokawa and T. Nishikubo, Kobunshi Ronbunshu, 44, 641 (1987).

11. S. H. Chen and Y. F. Maa, Macromolecules, 21, 904 (1988).

12. T. Nishikubo, T. Iizawa, A. Takahashi, and T. Shimokawa, $J$. Polym. Sci., Part A, Polym. Chem., 28, 105 (1990).

13. T. Nishikubo and K. Ozaki, Polym. J., 22, 1043 (1990). 